\title{
Oligofructose and long-chain inulin: influence on the gut microbial ecology of rats associated with a human faecal flora
}

\author{
Brigitta Kleessen*, Ludger Hartmann and Michael Blaut \\ German Institute of Human Nutrition (DIFE) Potsdam-Rehbrücke, Department of Gastrointestinal Microbiology, D-14558 \\ Bergholz-Rehbrücke, Germany \\ (Received 14 August 2000 - Revised 5 January 2001 - Accepted 17 April 2001)
}

\begin{abstract}
Dietary incorporation of fermentable, indigestible fructans may be of benefit to gastrointestinal health by providing short-chain fatty acids, stimulating the proliferation of bifidobacteria or lactobacilli and suppressing potential pathogenic organisms in the gut. We tested the hypothesis that the effects of fructans on caecal, colonic and faecal short-chain fatty acid concentration and microflora composition depend on their chain length. Germ-free rats associated with a human faecal flora were randomly assigned to one of four treatments as follows: (1) commercial standard diet as a control (Con); (2) Con+50 g short-chain oligofructose/kg (OF); (3) C+50 g long-chain inulin $/ \mathrm{kg}(\mathrm{lcIN})$; or (4) Con $+50 \mathrm{~g} \mathrm{OF}-\mathrm{lcIN} / \mathrm{kg}$ (Mix OF-lcIN). Changes in bacterial population groups in response to feeding these diets were investigated with 16S rRNA-targeted probes applied in in situ hybridization. Mix OF-lcIN- and lcIN-containing diets resulted in larger numbers of caecal, colonic and faecal bacteria of the Clostridium coccoides-Eubacterium rectale cluster than Con (10.6 and $10 \cdot 3 v \cdot 9 \cdot 5 \log _{10} / \mathrm{g}$ wet wt), whereas OF alone did not affect this bacterial group in caecum, colon or faeces. A bifidogenic effect was only observed in the colon and faeces of OF-treated rats. More lactobacilli were found in caecal and colonic contents of Mix $\mathrm{OF}-\mathrm{lcIN}-\mathrm{fed}$ rats and in faeces of OF-fed rats compared with Con. Mix OF-lcIN and OF led to significantly smaller numbers of caecal, colonic and faecal bacteria belonging to the Clostridium histolyticum and $C$. lituseburense groups than Con $\left(6.8\right.$ and $6.9 v .7 .9 \log _{10} / \mathrm{g}$ wet wt). Counts of total bacteria, Bacteroides-Prevotella and Enterobacteriaceae did not differ between the groups. OF and/or lcIN-containing diets significantly increased the caecal and colonic concentration of butyrate and its relative molar proportion. Only lcIN-containing diets resulted in a higher faecal concentration of butyrate than Con. Higher molar proportions of faecal butyrate were observed with all diets that had been supplemented with OF and/or lcIN. Stimulation of butyrate production could be of interest for the prevention of ulcerative colitis and colon cancer.
\end{abstract}

Butyrate: Oligofructose: Inulin: Intestinal microflora: Gnotobiotic rats

The recent commercialization of inulin (IN) and oligofructose $(\mathrm{OF})$ as food ingredients and fat replacers has served to focus much research on the influence of these substrates on the intestinal ecosystem and colonic function (Roberfroid, 2000). IN and OF occur in plants such as chicory, leek, onion, garlic, artichoke and asparagus at high levels (Roberfroid \& Delzenne, 1998; Van Loo et al. 1995). IN and OF are not digested by mammalian enzymes in the alimentary tract, thus contributing to the amount of fermentable carbohydrates in caecum and colon (Alles et al. 1996; Roberfroid, 1997). Fermentation of OF and IN in the gut may favour the production of short-chain fatty acids (SCFA) such as acetate, propionate and butyrate and sometimes of lactate (Cummings \& Macfarlane, 1997). The role of SCFA in the physiology of the colon is well known. Besides being involved in colonic $\mathrm{Na}$ and water absorption, SCFA are an important energy source for the colonocytes with butyrate being their preferred substrate and have a trophic effect on the colonic mucosa (Roediger, 1995). Butyrate also contributes to the maturation of colonic epithelium, to regeneration of the mucosa in the case of atrophy (Sakata, 1987), induces cell differentiation and stimulates apoptosis of cancerous cells (Hague et al. 1996). Therefore, butyrate is thought to play an important role as a preventative agent in colon carcinogenesis and/or ulcerative colitis. Based on these effects the stimulation of bacterial

Abbreviations: Con, control; DP, degree of polymerization; HFA, human flora-associated; IN, inulin; lc, long-chain; Mix OF-lnIN, oligofructose-long-chain inulin $(1: 1, w / w)$; OF, oligofructose; SCFA, short-chain fatty acid.

* Corresponding author: Dr Brigitta Kleessen, fax +49 3317406 950, email b.kleessen@gmx.de 
butyrate formation by dietary means is of particular interest. Animal studies have shown that the absolute concentration and molar proportion of butyrate and their distribution along the intestine varied between different sources of oligosaccharides (Campbell et al. 1997). Based on these findings, it may be hypothesised that specific IN-type fructans may be especially effective in raising the butyrate concentration in the colon.

Interest in IN and OF for human nutrition also stems from the prebiotic properties of these carbohydrates. Prebiotics are defined as non-digestible food ingredients, that beneficially affect the host by selectively stimulating the growth and/or activity of one or a limited number of potentially health-promoting bacteria in the large intestine (Gibson \& Roberfroid, 1995; Van Loo et al. 1999). Previous in vitro and in vivo studies have demonstrated that IN and OF selectively stimulate the growth of bifidobacteria or lactobacilli, both of which are considered to be beneficial to the host (Hidaka et al. 1986; Wang \& Gibson, 1993; Gibson et al. 1995; Bouhnik et al. 1996, 1999; Campbell et al. 1997; Djouzi \& Andrieux, 1997; Kleessen et al. 1997; Sghir et al. 1998; Kruse et al. 1999; Le Blay et al. 1999; Menne et al. 2000). These bacteria are recognised for creating conditions unfavourable for the growth of potentially pathogenic organisms, such as enterobacteria and certain clostridia (Gibson \& Wang, 1994; Roberfroid, 1997), and for forming potentially toxic or carcinogenic compounds (Buddington et al. 1996).

Taking into account all these aspects, there is a need to understand better the role of IN and OF in modulating the interactions between intestinal microflora and health. With a view toward an increasing butyrogenic effect in the gut the question arises as to whether the chemical and structural composition of the fructose-based non-digestible carbohydrates, e.g. differences in chain length, may influence the composition of the intestinal microflora and the microbial fermentations products in various segments of the gastrointestinal tract. The purpose of this study was therefore to compare effects of OF, long-chain (lc) IN and a mixture of these fructans on caecal, colonic and faecal SCFA concentration, $\mathrm{pH}$, total large bowel wt and wall wt, and gut microflora in human flora-associated (HFA) rats.

\section{Materials and methods}

\section{Fructans}

Raftilose ${ }^{\circledR}$ P95 and Raftiline ${ }^{\circledR}$ HP which contained mainly OF $(950 \mathrm{~g} / \mathrm{kg})$ and IN (995 g/kg) respectively, were supplied by the Raffinerie Tirlemontoise, Tienen, Belgium. Raftilose (OF), which is produced by partial enzymatic hydrolysis of chicory IN, is a mixture of $\beta(2-1)$ fructans with a degree of polymerization (DP) ranging between 3 and 7 (average DP of 4). Raftiline ${ }^{\circledR}$ HP is lc chicory IN devoid of fructans with the lower DP. The DP of Raftiline ${ }^{\circledR}$ HP ranges between 10 and 60 (average DP of 25). This choice of test substrates thus allowed us to investigate effects of DP on microflora composition and SCFA concentration.

\section{Animals and diets}

All treatments and diets were approved by the Ministry of Nutrition, Agriculture, and Forestry, Brandenburg, Germany (permission 48-3560-0/3). Twenty-four male 5-week-old germ-free Wistar rats (inbred strain AVNIpcv; DIfE, Bergholz-Rehbrücke, Germany) with an initial body weight of 122 (SD 9) g were randomly divided into four groups of six animals. Rats were maintained in positive-pressure isolators (Metall \& Plastik, Radolfzell, Germany) equipped with a sterile water supply and housed in macrolon cages on wire grates at a temperature of $22 \pm$ $2{ }^{\circ} \mathrm{C}$, relative humidity $55 \pm 5 \%$ and on a $12 \mathrm{~h}$ light-dark cycle (07.00-19.00 hours). They were given free access to water and a commercial standard diet (Altromin fortified ${ }^{\circledR}$ 1310; Altromin, Lage, Germany) with the following composition (according to the manufacturers) $(\mathrm{g} / \mathrm{kg})$ : crude protein 225 , crude fat 50 , ash 65 , moisture 135 , $\mathrm{N}$-free extract 480 . Gross energy was $12.5 \mathrm{MJ} / \mathrm{kg}$ diet. Rats were associated with bacteria by applying $3 \mathrm{ml}$ 1:10 dilution of fresh human faeces from a healthy male subject (age 30 years). Ten days after inoculation, the rats were divided into four groups. During a $7 \mathrm{~d}$ adaptation period treatments were as follows: (1) control diet (Altromin fortified ${ }^{\circledR} 1310$ ) (Con); (2) control diet+25 g Raftilose ${ }^{\circledR}$ P95/kg (OF); (3) control diet+25 g Raftiline ${ }^{\circledR} \mathrm{HP} / \mathrm{kg}$ (lcIN); (4) control diet+25 g Raftilose ${ }^{\circledR}$ P95 - Raftiline ${ }^{\circledR}$ HP $(1: 1, w / w) / k g$ (Mix OF-lcIN). Subsequently, the first group was fed on Con for $8 \mathrm{~d}$ (experimental period). The other three groups received the diet containing $50 \mathrm{~g}$ fructans $(\mathrm{OF}, \mathrm{lcIN}$, Mix $\mathrm{OF}-\mathrm{lcIN}) / \mathrm{kg}$. The diets were sterilized by irradiation at $25 \mathrm{kGy}$ in plastic bags. Food intake was determined daily and body weight was recorded every $2 \mathrm{~d}$.

Total dietary fibre content in the experimental diets was determined by the enzymic-gravimetric Association of Analytical Chemists' method (Prosky et al. 1988). In this method, fat-free material was treated with heat-stable $\alpha$ amylase, and then enzymically digested with protease and amyloglucosidase to remove protein and starch. Enzyme digesta was treated with four volumes ethanol $(780 \mathrm{ml} / \mathrm{l})$ to precipitate soluble dietary fibre. Total residue was filtered, washed with ethanol $(780 \mathrm{ml} / \mathrm{l})$, ethanol $(960 \mathrm{ml} / \mathrm{l})$ and acetone, dried and weighed. Residue value was corrected for protein and ash. The dietary fibre content of Con (without added fructans) was $87 \mathrm{~g} / \mathrm{kg}$ diet. For the other experimental diets, Con was partially replaced by fructans, resulting in a total dietary fibre content of 109.8 and $132.6 \mathrm{~g} / \mathrm{kg}$ diet during the adaptation and experimental periods respectively.

\section{Sampling}

Fresh faecal samples were collected at day 7 of the experimental period. For microbiological enumeration $0.5 \mathrm{~g}$ specimen was fixed as described previously (Kruse et al. 1999). About $0 \cdot 2 \mathrm{~g}$ sample was immediately frozen at $-80^{\circ} \mathrm{C}$ for analysis of lactate. For analysing SCFA, $0 \cdot 2 \mathrm{~g}$ specimen was prepared as described by Kruse et al. (1999). The residual material was used for $\mathrm{pH}$ measurement and DM estimation. At the end of the experimental period, rats were killed by decapitation. The caecum and colon were 
aseptically removed from the abdominal cavity and dissected free from fat and mesentery. Caecal and colonic contents were collected, weighed, $\mathrm{pH}$ measured, and aliquots were immediately processed for bacterial enumeration, analysis of lactate and SCFA, and DM estimation. Following removal of the intestinal contents, the tissues were cleaned with cold PBS, blotted and weighed to determine caecal and colonic wall weight.

\section{Bacterial enumeration}

Total bacteria and bacterial groups in the caecum, colon and faeces were enumerated by fluorescent in situ hybridization using the following $16 \mathrm{~S} / 23 \mathrm{~S}$ rRNA targeted oligonucleotide probes: (1) an equimolar mixture of five bacteria-directed probes (EUB 338, EUB 785, EUB 927, EUB 1055, EUB 1088) (Amann et al. 1995; Kleessen et al. 1999), referred to as EUB mix, to detect all bacteria; (2) Bac 303 to detect the Bacteroides-Prevotella cluster (Manz et al. 1996); (3) Erec 482 (S-*-Erec-0482-a-A-19) specific for most of the clostridia and eubacteria belonging to the Clostridium coccoides-Eubacterium rectale group (Franks et al. 1998); (4) the bifidobacterial probe Bif 164 (S-G-Bif-0164-a-A-18) (Langendijk et al. 1995); (5) Lab 158 (S-G-Lab-0158-aA20) for nearly all species of the genera Lactobacillus and Enterococcus in the gut (Harmsen et al. 1999); (6) Efs (L-*Efs-0343-a-A-18) to distinguish gut enterococci, i.e. Enterococcus faecalis among the Lab 158 (Beimfohr et al. 1993); (7) Ec 1531(L-S-Eco-1531-a-A-21) specific for a number of Enterobacteriaceae (e.g. Escherichia coli, Klebsiella pneumonia) (Poulsen et al. 1995); (8) Chis 150 (S-*-Chis-0150-a-A-23) and (9) Clit 135 (S-*-0135-a-A-19) to detect bacteria of the Clostridium histolyticum group and the C. lituseburense group (Franks et al. 1998). The nonsense probe Non 338 was used as a control to monitor non-specific oligonucleotide binding (Amann et al. 1995). The oligonucleotides were purchased $5^{\prime}$ labelled with the indocarbocyanine dye $\mathrm{Cy} 3$ (Interactiva Biotechnologie $\mathrm{GmbH}$, Ulm, Germany).

Fluorescent in situ hybridization was done as described by Manz et al. (1993) with some modifications. For homogenization, fixed samples were treated for $4 \mathrm{~min}$ in a Uniprep-Gyrator (InViTek GmbH, Berlin, Germany) and spotted on single wells of 3-aminopropyltriethoxysilanecoated slides (2 $\mathrm{g}$ 3-aminopropyltriethoxysilane in $99 \mathrm{ml}$ methanol), and allowed to air-dry. To improve permeabilization of the cell envelope, samples were treated with $10 \mu \mathrm{l}$ lysozyme buffer (100 mM-Tris- $\mathrm{HCl}$ (pH 8.0), $50 \mathrm{~mm}$-EDTA, $1 \mathrm{mg}$ lysozyme (130000 U/mg; Boehringer, Mannheim, Germany) and incubated on ice for $10 \mathrm{~min}$. Hybridizations were performed for $16 \mathrm{~h}$ at $46^{\circ} \mathrm{C}\left(50^{\circ} \mathrm{C}\right)$ in humid chambers after addition of $10 \mu l$ hybridization buffer (0.9 M-NaCl, 0.1 g SDS/l and $10 \mathrm{mM}-$ Tris-HCl, $\mathrm{pH} 7.4)$ containing $5 \mathrm{ng}$ probe/ $\mu \mathrm{l}$. After washing the hybridization slides in hybridization buffer for $20 \mathrm{~min}$ at $48^{\circ} \mathrm{C}\left(52^{\circ} \mathrm{C}\right)$, and subsequent treatment with the SlowFade ${ }^{\circledR}$ Antifade Kit (Molecular Probes, Leiden, The Netherlands) they were examined with a Carl Zeiss Axioplan epifluorescence microscope (Carl Zeiss, Jena, Germany) equipped with a $100 \times 1.30$ Plan Neofluar Ph3 oil immersion objective, an HBO $100 \mathrm{~W} / 3 \mathrm{Hg}$ lamp, the filter block 15, and a 12-bit cooled CCD camera (Sensicam 370 KL, PCO Kelheim, Germany). Images were taken and fluorescent cells were counted with the image analysis system KS400 Release 3.0 (Carl Zeiss). The microbial counts are expressed as $\log _{10}$ organisms/g wet wt.

\section{Short-chain fatty acids and lactate}

SCFA were extracted as described previously by Kruse $e t$ al. (1999). Samples of $1 \mu l$ were injected into a GC (HP 5890 A; Hewlett Packard GmbH, Waldbronn, Germany) equipped with a flame-ionization detector and a capillary column $(25 \mathrm{~m} \times 0.23 \mathrm{~mm})$ impregnated with $20 \mathrm{M}$ Carbowax (Hewlett Packard $\mathrm{GmbH}$ ). The carrier gas was He at a column flow rate of $12 \mathrm{ml} / \mathrm{min}$ with a split ratio of 1:10. The column temperature was $125^{\circ} \mathrm{C}$. Isobutyric acid served as an internal standard. Lactate was determined enzymically using L- and D-lactate dehydrogenases (Kit 1112821; Boeringer Mannheim). For DM estimation intestinal samples were freeze-dried to constant weight under vacuum.

\section{Statistics}

The Statistical Package for Social Science (SPSS for Windows, version 8.0; SPSS Inc., Chicago, IL, USA) was used to determine if variables differed among treatment groups. Two-way ANOVA was performed to assess the effects of diet (Con, OF, lcIN, Mix OF-lcIN), of segment (caecum, colon and faeces) and of the interaction between diet and segment (Wilcoxon \& Wilcox, 1964). When the ANOVA indicated that significant treatment effects had occurred the least significant difference test was used to locate differences between treatment means. In the tables, results are presented as mean values with their standard errors. Data were checked for normality before statistical analysis was performed (Zar, 1984). Bacteriological results were transformed- $\log _{10}$ to improve the homogeneity of variance. Differences were considered to be significant at $P<0.05$.

\section{Results \\ Feed intake and body-weight gain}

Rats were generally in good health throughout the experiment. There were no differences in feed intake or body-weight gain among the treatment groups. The mean feed intake in the experimental period was $23 \cdot 1-23 \cdot 7 \mathrm{~g} / \mathrm{d}$ (SEM 0.4). The mean body-weight gain of the rats ranged from 14.2 to $14.8 \mathrm{~g} / 2 \mathrm{~d}$ (SEM 0.6). There were no growth differences at any interval throughout the study (results not shown).

\section{Total large bowel content, wall weight, DM, $\mathrm{pH}$ and faecal excretion}

Addition of OF and lcIN to the diet led to greater wet content and wall weight of the caecum compared with control (Con) rats (Table 1). Wet content of the colon was higher $(P<0.05)$ in rats consuming the lcIN diet than in 
Table 1. Caecal and colonic content and wall weights, $\mathrm{DM}, \mathrm{pH}$ and faecal output in rats associated with a human faecal flora†

(Mean values for six rats per group)

\begin{tabular}{|c|c|c|c|c|c|}
\hline \multirow[b]{2}{*}{ Segment } & \multicolumn{4}{|c|}{ Dietł } & \multirow[b]{2}{*}{ Pooled SEM } \\
\hline & Control & OF & IcIN & Mix OF-IcIN & \\
\hline \multicolumn{6}{|l|}{ Wet content (g) } \\
\hline Caecum & $5 \cdot 76$ & $7 \cdot 78$ & $7 \cdot 24$ & $8.34^{*}$ & 0.51 \\
\hline Colon & $2 \cdot 44$ & $2 \cdot 87$ & $3.85^{\star}$ & $2 \cdot 60$ & 0.25 \\
\hline \multicolumn{6}{|l|}{ Wall weight (g) } \\
\hline Caecum & $1 \cdot 30$ & 1.64 & 1.51 & $1.87^{*}$ & 0.05 \\
\hline Colon & $1 \cdot 16$ & 1.51 & 1.32 & 1.42 & 0.05 \\
\hline \multicolumn{6}{|l|}{$\mathrm{pH}$} \\
\hline Caecum & $6 \cdot 40$ & $5 \cdot 71^{*}$ & $5 \cdot 65^{\star}$ & $6 \cdot 31$ & 0.08 \\
\hline Colon & $6 \cdot 25$ & $5 \cdot 75^{\star}$ & $5 \cdot 61^{*}$ & 6.00 & 0.06 \\
\hline Faeces & $6 \cdot 07$ & 5.92 & $6 \cdot 16$ & $6 \cdot 19$ & 0.05 \\
\hline \multicolumn{6}{|l|}{$\mathrm{DM}(\mathrm{g} / \mathrm{kg})$} \\
\hline Caecum & 235.6 & 195.9 & $202 \cdot 0$ & $216 \cdot 0$ & $5 \cdot 1$ \\
\hline Colon & $275 \cdot 6$ & $246 \cdot 4$ & $234 \cdot 2$ & $228 \cdot 8$ & $4 \cdot 2$ \\
\hline Faeces & 345.5 & $275 \cdot 1$ & 293.2 & $264 \cdot 9^{\star}$ & $10 \cdot 8$ \\
\hline Faecal output (g wet wt/d) & 11.00 & $12 \cdot 97^{*}$ & $12 \cdot 67^{*}$ & $13 \cdot 34^{*}$ & 0.22 \\
\hline
\end{tabular}

OF, oligofructose (Raftilose ${ }^{\circledR}$ P95; Raffiniere Tirlemontoise, Tienen, Belgium); IcIN, long-chain inulin (Raftiline ${ }^{\circledR}$ HP; Raffiniere Tirlemontoise); Mix OF-IcIN, OF-IcIN (1:1, w/w).

Mean values were significantly different from those for the control group: * $P<0.05$.

$\dagger$ For details of diets and procedures, see p. 292.

‡Differences among treatment groups were analysed by one-way ANOVA followed by Scheffe's test for mutiple comparison.

rats on the Con diet. Colonic wall weights were unaffected by diets. The percentage faecal DM was lower $(P<0 \cdot 05)$ in rats fed Mix OF-lcIN than in rats on the Con diet (Table 1). Caecal and colonic $\mathrm{pH}$ was lower $(P<0.05)$ in rats consuming OF or lcIN diet compared with the Con diet. No significant differences among groups were noted in faecal $\mathrm{pH}$. Faecal output was higher in rats consuming fructancontaining diets than Con due to increased water excretion.

\section{Bacterial enumeration}

The effects of treatments on caecal, colonic and faecal microflora of rats are presented in Table 2. Total bacterial counts/g wet weight did not differ, but there were differences with respect to counts of certain bacterial groups. Caecal, colonic and faecal counts of bacteria belonging to the Clostridium coccoides-Eubacterium rectale cluster were significantly $(P<0.05)$ higher in rats consuming Mix OF-lcIN than in the rats consuming Con. Bacteria of this group also tended $(P=0 \cdot 062)$ to be higher in rats fed lcIN than in rats fed Con but did not differ in rats fed OF. The OF-containing diet resulted in higher numbers of bifidobacteria $(P<0.05)$ in the colon than Con and in a trend $(P=0.052)$ to higher counts in the faeces, whereas the numbers observed in the caecum were not statistically different. In contrast, rats consuming the lcIN-containing diet had fewer $(P<0.05)$ bifidobacteria in the caecum compared with rats receiving the Con diet. The numbers of bifidobacteria were unaffected by Mix OF-lcIN treatment. Rats fed Mix OF-lcIN, however, had higher $(P<0.05)$ caecal and colonic numbers of Lactobacillus compared with Con. In contrast, rats consuming OF displayed higher $(P<$ 0.05) numbers of Lactobacillus and Enterococcus in faeces compared with Con-fed rats. Mix OF-lcIN and OF led to smaller $(P<0.05)$ numbers of bacteria belonging to the
Clostridium histolyticum and C. lituseburense groups than Con. No significant differences among groups were noted in numbers of Bacteroides-Prevotella and Enterobacteriaceae.

\section{Short-chain fatty acids and lactate}

Both the diet and the site of sampling in the gut (segment) affected the concentration of SCFA, and there were significant interactions between the effects (Table 3). The SCFA concentrations were always higher in caecal contents than in faeces $(P<0 \cdot 05)$. The caecal and colonic concentrations of butyrate were higher $(P<0.05)$ in all rats consuming OF and/or lcIN than in rats consuming Con. Only lcIN-containing diets (lcIN, Mix OF-lcIN), however, affected the faecal concentration of butyrate $(P<0.05)$. Moreover, rats fed lcIN had a higher $(P<0.05)$ caecal propionate concentration than Con. More acetate was found in colonic contents of OF-fed rats and in faeces of Mix OFlcIN-fed rats $(P<0.05)$. The molar ratios of SCFA in the intestinal samples differed with the diet (Table 4). The butyrate proportions were higher in all rats fed OF and/or lcIN than in those fed Con diet. Lower proportions of acetate $(P<0.05)$ were found in the caecal contents of lcIN-fed rats and in the faeces of Mix OF-lcIN-fed rats compared with Con. Moreover, OF and Mix OF-lcIN resulted in lower colonic propionate proportions. Caecal and faecal concentrations of lactate were unaffected by treatments (Table 3).

\section{Discussion}

Feeding trials with HFA rats were performed to investigate the influence of OF and/or lcIN on caecal, colonic and faecal microbiota and microbial fermentation products. Gnotobiotic rats were used for these investigations because intestinal 
Table 2. Effects of dietary oligofructose and inulin on caecal, colonic and faecal bacterial counts $\left(\log _{10}\right.$ counts/g wet weight) in rats associated with a human faecal flora†

(Mean values for six rats per group)

\begin{tabular}{|c|c|c|c|c|c|c|c|c|}
\hline \multirow[b]{2}{*}{ Segment } & \multicolumn{4}{|c|}{ Diet } & \multirow[b]{2}{*}{ Pooled SEM } & \multicolumn{3}{|c|}{ Statistical significance of effect of: $P$} \\
\hline & Control & OF & IcIN & Mix OF-IcIN & & Diet & Segment & Diet $\times$ Segment \\
\hline \multicolumn{9}{|c|}{ Total bacteria } \\
\hline Caecum & $10 \cdot 5$ & $10 \cdot 6$ & $10 \cdot 5$ & $10 \cdot 8$ & 0.05 & \multirow[t]{3}{*}{$0 \cdot 21$} & \multirow[t]{3}{*}{0.35} & \multirow[t]{3}{*}{0.97} \\
\hline Colon & $10 \cdot 7$ & $10 \cdot 7$ & $10 \cdot 7$ & $10 \cdot 8$ & 0.06 & & & \\
\hline Faeces & $10 \cdot 6$ & $10 \cdot 5$ & $10 \cdot 6$ & $10 \cdot 8$ & 0.07 & & & \\
\hline \multicolumn{9}{|c|}{ Bacteroides-Prevotella } \\
\hline Caecum & $10 \cdot 1$ & $10 \cdot 1$ & $9 \cdot 6$ & $9 \cdot 7$ & $0 \cdot 11$ & \multirow[t]{3}{*}{0.07} & \multirow[t]{3}{*}{0.08} & \multirow[t]{3}{*}{0.48} \\
\hline Colon & $9 \cdot 9$ & $10 \cdot 0$ & $9 \cdot 6$ & $9 \cdot 7$ & 0.08 & & & \\
\hline Faeces & $10 \cdot 2$ & 9.9 & $10 \cdot 0$ & $9 \cdot 6$ & 0.07 & & & \\
\hline \multicolumn{9}{|c|}{ Clostridium coccoides-Eubacterium rectale cluster } \\
\hline Caecum & 9.6 & 9.9 & $10 \cdot 2$ & $10 \cdot 6^{*}$ & $0 \cdot 10$ & \multirow[t]{3}{*}{0.0001} & \multirow[t]{3}{*}{0.51} & \multirow[t]{3}{*}{0.79} \\
\hline Colon & 9.5 & $9 \cdot 8$ & $10 \cdot 4$ & $10 \cdot 6^{*}$ & $0 \cdot 11$ & & & \\
\hline Faeces & $9 \cdot 4$ & $9 \cdot 9$ & $10 \cdot 3$ & $10 \cdot 6^{*}$ & 0.09 & & & \\
\hline \multicolumn{9}{|c|}{ Clostridium histolyticum group and $C$. lituseburense group } \\
\hline Caecum & $8 \cdot 1$ & $6 \cdot 8^{*}$ & $7 \cdot 5$ & $7 \cdot 1^{*}$ & $0 \cdot 15$ & \multirow[t]{3}{*}{0.0001} & \multirow[t]{3}{*}{0.41} & \multirow[t]{3}{*}{0.69} \\
\hline Colon & $7 \cdot 7$ & $7 \cdot 1$ & $7 \cdot 4$ & $6 \cdot 5^{*}$ & $0 \cdot 15$ & & & \\
\hline Faeces & 8.0 & $7 \cdot 0^{*}$ & $7 \cdot 4$ & $6 \cdot 9^{*}$ & $0 \cdot 14$ & & & \\
\hline \multicolumn{9}{|c|}{ Bifidobacterium } \\
\hline Caecum & 8.6 & $9 \cdot 2$ & $7 \cdot 4^{\star}$ & $9 \cdot 0$ & $0 \cdot 17$ & \multirow[t]{3}{*}{0.0001} & \multirow[t]{3}{*}{$0 \cdot 19$} & \multirow[t]{3}{*}{0.003} \\
\hline Colon & 8.5 & $9 \cdot 7^{*}$ & 8.4 & 8.7 & $0 \cdot 13$ & & & \\
\hline Faeces & 8.7 & $9 \cdot 6$ & $8 \cdot 2$ & $8 \cdot 3$ & $0 \cdot 15$ & & & \\
\hline \multicolumn{9}{|c|}{ Lactobacillus } \\
\hline Caecum & $8 \cdot 0$ & $8 \cdot 6$ & $8 \cdot 4$ & $9 \cdot 5^{*}$ & $0 \cdot 18$ & \multirow[t]{3}{*}{0.0001} & \multirow[t]{3}{*}{0.20} & \multirow[t]{3}{*}{0.011} \\
\hline Colon & $8 \cdot 3$ & 8.9 & $8 \cdot 7$ & $9 \cdot 8^{*}$ & $0 \cdot 16$ & & & \\
\hline Faeces & 8.0 & $9 \cdot 2^{*}$ & $8 \cdot 2$ & 8.7 & 0.17 & & & \\
\hline Enterococc & & & & & & & & \\
\hline Caecum & $7 \cdot 6$ & 8.0 & $7 \cdot 0$ & 7.5 & 0.20 & 0.001 & 0.42 & 0.48 \\
\hline Colon & 7.5 & 8.0 & 6.9 & $7 \cdot 7$ & 0.15 & & & \\
\hline Faeces & 7.0 & $8 \cdot 6^{*}$ & 7.5 & $8 \cdot 1$ & 0.17 & & & \\
\hline Enterobacte & iaceae & & & & & & & \\
\hline Caecum & $7 \cdot 5$ & $7 \cdot 2$ & $7 \cdot 8$ & $7 \cdot 7$ & $0 \cdot 13$ & 0.45 & $0 \cdot 18$ & 0.46 \\
\hline Colon & 7.5 & 7.5 & $7 \cdot 7$ & $7 \cdot 4$ & 0.09 & & & \\
\hline Faeces & $8 \cdot 1$ & 7.9 & $7 \cdot 8$ & 7.5 & 0.14 & & & \\
\hline
\end{tabular}

OF, oligofructose (Raftilose ${ }^{\circledR}$ P95; Raffiniere Tirlemontoise, Tienen, Belgium); IcIN, long-chain inulin (Raftiline ${ }^{\circledR}$ HP; Raffiniere Tirlemontoise); Mix OF-IcIN, OF-IcIN (1:1, w/w).

Mean values were significantly different from those of the control group: * $P<0.05$.

†For details of diets and procedures, see p. 292.

contents except faeces cannot be obtained easily from healthy human subjects without the application of invasive techniques which cannot be justified for ethical reasons. The HFA rat is a model allowing accessibility to caecal and colonic contents. This model was validated for fermentation studies of non-digestible fructans (Djouzi \& Andrieux, 1997). The similarity of the resultant flora to that of human faeces has been investigated at bacteriological and metabolic levels (Mallet et al. 1987; Rumney \& Roland, 1992). In our present study, rats fed the control diet kept the major characteristics of the human donor in terms of bacterial population (e.g. numbers of bacteria belonging to the dominant flora: Clostridium coccoides-Eubacterium rectale cluster, Bacteroides-Prevotella, bifidobacteria) and metabolic profile (Tables 2-4). The HFA rat model facilitates studies of the interaction between dietary fructans and the human gut flora, since it is easier to control and manipulate animal diets than those of human subjects.

To our knowledge, this is the first study which exploits the fluorescent in situ hybridization-technology using a panel of ten different $16 \mathrm{~S} / 23 \mathrm{~S}$ rRNA targeted oligonucleotide probes for determining gut bacteria in HFA rats on a quantifiable basis. This method has made it possible to enumerate bacterial populations without prior cultivation. In particular the occurrence of obligately anaerobic bacteria such as Eubacterium sp. may be considerably underestimated when cultivation-based enumeration techniques are used. Therefore, fluorescent in situ hybridization leads to a major improvement in our current knowledge of the composition of the intestinal microflora (Welling et al. 1997).

The feeding of OF and/or lcIN to HFA rats resulted in a number of changes in caecal, colonic and faecal variables, most notably, variations in microflora composition (Tables 1-4). One important finding of the study concerns the increase in bacteria belonging to the Clostridium coccoides-Eubacterium rectale cluster in rats consuming lcIN-containing diets compared with Con. During the period of Mix OF-lcIN ingestion, these organisms increased as a proportion of the total flora from $13 \%$ to $63 \%$, displacing Bacteroides-Prevotella as the predominant micro-organisms in the caecum. It is tempting to speculate that the selective stimulation of the Clostridium coccoidesEubacterium rectale group by $\mathrm{lcIN}$ or Mix $\mathrm{OF}-\mathrm{lcIN}$, but 
Table 3. Effects of dietary oligofructose and long-chain inulin on caecal, colonic and faecal concentrations ( $\mu \mathrm{mol} / \mathrm{g}$ wet wt) of short-chain fatty acids (SCFA) and lactate in rats associated with a human faecal flora

(Mean values for six rats per group)

\begin{tabular}{|c|c|c|c|c|c|c|c|c|}
\hline \multirow[b]{2}{*}{ Segment } & \multicolumn{4}{|c|}{ Diet } & \multirow[b]{2}{*}{ Pooled SEM } & \multicolumn{3}{|c|}{ Statistical significance of effect of: $P$} \\
\hline & Control & OF & IcIN & Mix OF-IcIN & & Diet & Segment & Diet $\times$ Segment \\
\hline \multicolumn{9}{|l|}{ Total SCFA } \\
\hline Caecum & 84.4 & $99 \cdot 4^{*}$ & $103 \cdot 8^{*}$ & $98.3^{*}$ & 1.9 & \multirow[t]{3}{*}{0.0001} & \multirow[t]{3}{*}{0.0001} & \multirow[t]{3}{*}{0.09} \\
\hline Colon & 68.6 & $87 \cdot 1^{*}$ & 81.9 & $85 \cdot 8^{*}$ & $2 \cdot 1$ & & & \\
\hline Faeces & $59 \cdot 3$ & 61.9 & $63 \cdot 7$ & $59 \cdot 2$ & 1.6 & & & \\
\hline \multicolumn{9}{|l|}{ Acetate } \\
\hline Caecum & $49 \cdot 8$ & $55 \cdot 4$ & $45 \cdot 9$ & $51 \cdot 2$ & $1 \cdot 3$ & \multirow[t]{3}{*}{0.006} & \multirow[t]{3}{*}{0.0001} & \multirow[t]{3}{*}{0.004} \\
\hline Colon & $41 \cdot 1$ & $50 \cdot 8^{*}$ & $42 \cdot 5$ & $46 \cdot 7$ & 1.2 & & & \\
\hline Faeces & $37 \cdot 4$ & $35 \cdot 1$ & 35.6 & $27 \cdot 6^{*}$ & 1.3 & & & \\
\hline \multicolumn{9}{|l|}{ Propionate } \\
\hline Caecum & $21 \cdot 1$ & $22 \cdot 8$ & $32 \cdot 5^{\star}$ & $19 \cdot 1$ & 0.8 & \multirow[t]{3}{*}{0.01} & \multirow[t]{3}{*}{0.0001} & \multirow[t]{3}{*}{0.06} \\
\hline Colon & $18 \cdot 2$ & $17 \cdot 8$ & 21.3 & $16 \cdot 8$ & 0.7 & & & \\
\hline Faeces & 14.7 & $15 \cdot 5$ & 14.4 & $15 \cdot 8$ & 0.4 & & & \\
\hline \multicolumn{9}{|l|}{ Butyrate } \\
\hline Caecum & $13 \cdot 4$ & $21 \cdot 3^{*}$ & $25 \cdot 4^{*}$ & $28 \cdot 0^{*}$ & $1 \cdot 3$ & \multirow[t]{3}{*}{0.0001} & \multirow[t]{3}{*}{0.0001} & \multirow[t]{3}{*}{0.3} \\
\hline Colon & $9 \cdot 3$ & $18 \cdot 6^{*}$ & $18 \cdot 1^{*}$ & $22 \cdot 3^{*}$ & $1 \cdot 2$ & & & \\
\hline Faeces & 7.1 & 11.4 & $13 \cdot 6^{*}$ & $15 \cdot 7^{*}$ & 0.9 & & & \\
\hline \multicolumn{9}{|l|}{ Lactate } \\
\hline Caecum & $5 \cdot 8$ & 9.2 & $8 \cdot 8$ & 8.7 & 0.7 & \multirow[t]{3}{*}{0.5} & \multirow[t]{3}{*}{0.05} & \multirow[t]{3}{*}{0.2} \\
\hline Colon & 4.5 & 7.6 & $7 \cdot 7$ & 6.9 & 0.4 & & & \\
\hline Faeces & 3.6 & 4.9 & 4.6 & 4.9 & $1 \cdot 1$ & & & \\
\hline
\end{tabular}

not by OF alone, is based on a highly efficient enzyme system for the utilization of lcIN which enables members of the Clostridium coccoides-Eubacterium rectale group to compete successfully with other bacterial groups in the gut ecosystem.

Moreover, it is noteworthy that the feeding of OFcontaining diets resulted in a significant decrease of bacteria, belonging to the Clostridium histolyticum or C. lituseburense groups, e.g. C. perfringens. A high proportion of these organisms may be pathogenic, e.g. through their proteolytic capabilities and toxin production. An increased SCFA-production through bacterial fermentation of non-digestible carbohydrates such as OF or lcIN and the resulting decrease in caecal and colonic $\mathrm{pH}$ (Table 1) is an accepted mechanism for the inhibition of pathogens (Hentges, 1967). However, Gibson \& Wang (1994) pointed out that acidity may not be the sole mechanism of inhibition. The authors showed by fermentation experiments that even

Table 4. Effects of dietary oligofructose and long-chain inulin on caecal, colonic and faecal molar ratios of acetate, propionate and butyrate in rats associated with a human faecal flora†‡

(Mean values for six rats per group)

\begin{tabular}{|c|c|c|c|c|c|c|c|c|}
\hline \multirow[b]{2}{*}{ Segment } & \multicolumn{4}{|c|}{ Diet } & \multirow[b]{2}{*}{ Pooled SEM } & \multicolumn{3}{|c|}{ Statistical significance of effects of: $P$} \\
\hline & Control & OF & IcIN & Mix OF-IcIN & & Diet & Segment & Diet $\times$ Segment \\
\hline \multicolumn{9}{|l|}{ Acetate } \\
\hline Caecum & $59 \cdot 1$ & $55 \cdot 8$ & $44 \cdot 2^{*}$ & 51.9 & $1 \cdot 2$ & 0.0001 & 0.2 & 0.01 \\
\hline Colon & $59 \cdot 6$ & $58 \cdot 3$ & $52 \cdot 0$ & $54 \cdot 7$ & 1.0 & & & \\
\hline Faeces & $62 \cdot 8$ & $56 \cdot 4$ & $56 \cdot 0$ & $47 \cdot 0^{\star}$ & 1.6 & & & \\
\hline \multicolumn{9}{|l|}{ Propionate } \\
\hline Caecum & $25 \cdot 0$ & $22 \cdot 9$ & $31 \cdot 3$ & $19 \cdot 5$ & $1 \cdot 0$ & 0.002 & 0.2 & 0.01 \\
\hline Colon & $26 \cdot 8$ & $20 \cdot 4^{*}$ & $25 \cdot 9$ & $19 \cdot 4^{*}$ & 0.8 & & & \\
\hline Faeces & $25 \cdot 2$ & $25 \cdot 3$ & $22 \cdot 7$ & $26 \cdot 7$ & 0.8 & & & \\
\hline \multicolumn{9}{|l|}{ Butyrate } \\
\hline Caecum & $15 \cdot 9$ & 21.3 & $24 \cdot 5^{\star}$ & $28 \cdot 6^{*}$ & 1.2 & 0.0001 & 0.06 & 0.8 \\
\hline Colon & $13 \cdot 6$ & $21 \cdot 3^{*}$ & $22 \cdot 1^{*}$ & $25 \cdot 9^{*}$ & $1 \cdot 1$ & & & \\
\hline Faeces & $12 \cdot 0$ & $18 \cdot 3^{*}$ & $21 \cdot 3^{*}$ & $26 \cdot 3^{*}$ & 1.4 & & & \\
\hline
\end{tabular}

OF, oligofructose (Raftilose ${ }^{\circledR}$ P95; Raffiniere Tirlemontoise, Tienen, Belgium); IcIN, long-chain inulin (Raftiline ${ }^{\circledR}$ HP; Raffiniere Tirlemontoise); Mix OF-IcIN, OF-IcIN (1:1, w/w).

Mean values were significantly different from those of the control group: ${ }^{\star} P<0.05$.

† For details of diets and procedures, see p. 292

¥ Molar ratio, mol/100 mol short-chain fatty acids (acetate+propionate+butyrate). 
at a neutral $\mathrm{pH}$ level clostridia were inhibited when cocultured with Bifidobacterium infantis. Therefore, the production of inhibitory substances such as bacteriocins by the bifidobacteria is assumed. Feeding of OF-containing diets also resulted in a stimulation of Lactobacillus (Table 2). The increase in lactobacilli detected in rats fed Mix OFlcIN was, however, restricted to caecal and colonic contents and in rats fed OF to the faeces. A similar observation was made by Le Blay et al. (1999) using fructooligosaccharides in a long-term experiment with conventional rats. The expected bifidogenic effects, however, were only restricted to the colon and faeces of the OF-treated rats. These observations are seemingly in contradiction to previous own investigations using IN in human subjects (Kleessen et al. 1997; Kruse et al. 1999), in vitro work by others (Wang \& Gibson, 1993), in vivo studies in HFA rats (Djouzi \& Andrieux, 1997), and studies on human subjects (Gibson et al. 1995). These discrepancies may be explained as follows: First, in all these studies, IN with an average DP of $8-10$ and not lcIN with an average DP of 25 has been used. Second, bifidobacteria do not have a highly efficient enzyme system for the utilization of lcIN (Roberfroid et al. 1998). Third, it is still an open question as to whether the initial number of bifidobacteria in the faeces influences the extent of stimulation of bifidobacteria in response to the consumption of IN (Roberfroid et al. 1998; Rao, 1999). In our present study, the high level of bifidobacteria both in the human faecal inoculum $\left(9.0 \log _{10} / \mathrm{g}\right.$ wet faeces) and in the initial faecal samples of HFA rats $\left(8.7 \log _{10} / \mathrm{g}\right.$ wet faeces) may be responsible for the lack of increase in bifidobacterial numbers in response to lcIN (Table 2).

The marked differences in rat caecal, colonic and faecal microflora of rats in response to feeding of OF and/or lcIN confirm that modifications in the chain length of fructans have the potential to change the composition of the intestinal microflora. Despite the evidence that the gut flora composition is affected by the administration of OF or lcIN, it is difficult to identify those bacterial species that are responsible for these changes. This difficulty arises from the fact that complex carbohydrates, such as lcIN, are metabolized in a process based on cross-feeding by the microflora (Gibson, 1999).

Although it is generally accepted that OF and IN are not metabolized by rat digestive enzymes in the small intestine and thus reach the caecum and colon, a partial bacterial hydrolysis and fermentation of these non-digestible fructans, at least of $\mathrm{OF}$, in the distal part of the small intestine of the HFA rats cannot be excluded. This view is supported by the ileal numbers of lactobacilli which tended to be higher in rats fed $\mathrm{OF}\left(2 \times 10^{8} / \mathrm{g}\right.$ wet wt $)$ than in control rats $\left(5 \times 10^{7} / \mathrm{g}\right.$ wet wt), but this difference was not significant (results not shown).

Several authors have reported that feeding OF or IN increases tissue weights and contents of the caecum (Andrieux et al. 1991; Campbell et al. 1997; Le Blay et al. 1999). Accordingly, we observed higher caecal contents and wall weights in rats fed OF and/or lcIN than in Con. This means that, on the one hand OF or lcIN are substrates, and thus nutrients for bacterial metabolism, and thereby cause an increase in bacterial mass. This is supported by higher numbers of total organisms in caecal digesta in the rats fed these diets as compared with Con diet. On the other hand, it has been suggested that fermentable polysaccharides or oligosaccharides cause marked caecal enlargement associated with an increase in mucosal cell proliferation. It has been argued that this trophic effect is due to increased bacterial metabolism leading to a reduction in intralumen $\mathrm{pH}$, or a direct stimulating effect of SCFA, mainly butyrate (Sakata, 1987). Increased production of SCFA within the large bowel may influence intestinal mucosal proliferation by increasing proglucagon mRNA expression and stimulating glucagon-like peptide-2 secretion (Massimino et al. 1998; Tappenden et al. 1998).

It should be noted, that OF and/or lcIN were included in the diets also at the expense of dietary fibre as shown by the Association of Analytical Chemists' method (Prosky et al. 1988. The bulking capacity of dietary fibre might have influenced the faecal weight in this study.

The high number of bacteria detected by fluorescent in situ hybridization in the caecum of rats reflects a considerable fermentation capacity in the caecum. Butyrate was particularly increased in rats fed Mix OF-lcIN or lcIN and considerably less in rats fed the Con diet. This is consistent with previous studies using OF or IN both in vitro (Gibson \& Wang, 1994) and in vivo (Campbell et al. 1997). The same applies to the molar proportion of butyrate to total SCFA. The molar proportion of colonic and faecal butyrate was also elevated in those rats that were fed any of the three supplemented diets. However, in contrast to the caecum and colon the increase in butyrate concentration in faeces was only detected in rats consuming lcIN-containing diets and was not paralleled by an increase in the total SCFA concentration. It is conceivable that the observed effect was not due to a reduced fermentation of fructans in the distal part of the colon but to an increased absorption of SCFA during the passage through the colon (Cummings, 1981; Cummings \& Macfarlane, 1991) and a shift of bacterial metabolic activity towards butyrate production. This would be consistent with the observed elevation of bacteria belonging to the Clostridium coccoides-Eubacterium rectale group. This pylogenetic group contains eubacteria and clostridia belonging to the XIVa cluster of grampositive bacteria as defined by Collins et al. (1994), e.g. species such as Eubacterium contortum, E. hadrum, E. ramulus, $E$. rectale or Clostridium coccoides, C. clostridiiformes and C. xylanolyticum (Franks et al. 1998). The molecular characterisation of butyrate-producing species from faecal samples of human volunteers by Barcenilla et al. (2000) has shown that most of the butyrateproducing isolates are related to the Clostridium coccoidesEubacterium rectale group.

The presence of butyrate in the colon may be important for the prevention of colon cancer (Weaver et al. 1988) or ulcerative colitis (Simpson et al. 2000). Cell culture studies show that the presence of butyrate at physiological concentrations enhances growth of normal cells and inhibits that of malignant ones (Velazquez et al. 1996). These actions are effected by a variety of mechanisms including promotion of DNA repair and differentiation of tumour cells (Smith et al. 1998). The induction of apoptosis in malignant cells is considered as a major effect of butyrate. A significant reduction in aberrant crypt numbers (the earliest 
preneoplastic lesions) was observed in azoxymethanetreated rats fed $1 \mathrm{CIN}$-and $\mathrm{OF}$-containing diets when compared with azoxymethane-treated control rats fed on a standard diet (Reddy et al. 1997). Ulcerative colitis may also relate to butyrate availability. Colonocytes isolated from colitis patients have an impaired capacity to oxidise butyrate in vitro (Burke et al. 1997). Faecal butyrate concentration is higher in colitis patients than in controls (Treem et al. 1994). These data suggest that there is a defect in butyrate metabolism which could be overcome through stimulation of butyrate formation by microbial fermentation of non-digestible carbohydrates such as resistant starch or fructans (Jacobasch et al. 1999).

It should be mentioned that the HFA rats in our study were fed a basic diet of natural ingredients, which was coarsely ground and contained $87 \mathrm{~g}$ dietary fibre $/ \mathrm{kg}$ of mainly cereal origin. Therefore, substrate interactions between $\mathrm{OF}$ and/or lcIN and fibre fermentation may have occurred in the caecum and colon, as was assumed previously for resistant starch and dietary fibre (Cummings et al. 1996; Morita et al. 1999). Such interactions might protect fructans from full fermentation in the caecum or proximal colon by slowing down the rate of fermentation. Moreover, Roberfroid et al. (1998), demonstrated in vitro that IN chains with DP $>10$ are fermented on average half as fast as $\mathrm{OF}$ with $\mathrm{DP}<10$. It may therefore be possible to control the caecal and colonic fermentation by modifying the chain length of dietary IN. Such dietary manipulations increase the butyrate production in the colon and may thereby contribute to the prevention of certain intestinal diseases such as ulcerative colitis and cancer.

To our knowledge, this is the first study which shows that fructan-containing diets increase the number of a bacterial population (Clostridium coccoides-Eubacterium rectale cluster) other than bifidobacteria or lactobacilli. To define the role of this group of organisms and to know their metabolic properties will be crucial for understanding their role in colonic metabolism and gut health. Whether organisms of this cluster have any health-promoting properties beyond their ability to produce butyrate needs to be established.

\section{Acknowledgements}

We want to express our thanks to Susanne Dietrich, Ines Grüner, Renate Herzog, Ute Lehmann and Elke Thom for taking care of the animals. The expert technical assistance of Sabine Schmidt, Bettina Junker and Bärbel Gruhl is acknowledged. The authors thank Dr Gerhard Dongowski for determination of the total dietary fibre content of experimental diets. This work was supported by European Research Project FAIR-CT-97-3035.

\section{References}

Alles MS, Hautfast JG, Nagengast FM, Hartemink R, Van Laere KM \& Jansen FM (1996) Fate of fructo-oligosaccharides in the human intestine. British Journal of Nutrition 76, 211-221.

Amann RI, Ludwig W \& Schleifer K-H (1995) Phylogenetic identification and in situ detection of individual microbial cells without cultivation. Microbial Reviews 59, 143-169.
Andrieux C, Lory S, Dufour-Lescoat CD, de Baynast R \& Szylit O (1991) Physiological effects of inulin in germ-free rats and in heteroxenic rats inoculated with a human flora. Food Hydrocolloids 5, 49-56.

Barcenilla A, Pryde SE, Martin JC, Duncan SH, Stewart CS, Henderson C \& Flint HJ (2000) Phylogenetic relationship of butyrate-producing bacteria from the human gut. Applied and Environmental Microbiology 66, 1654-1661.

Beimfohr C, Krause A, Amann RI, Ludwig W \& Schleifer K-H (1993) In situ identification of lactococci, enterococci and streptococci. Systematic and Applied Microbiology 16, 450-456.

Bouhnik Y, Flourie B, Andrieux C, Bisetti N, Briet F \& Rambaud J-C (1996) Effects of Bifidobacterium sp. fermented milk ingested with or without inulin on colonic bifidobacteria and enzymatic activities in healthy humans. European Journal of Clinical Nutrition 50, 269-273.

Bouhnik Y, Vahedi K, Achour L, Attar A, Salfati J, Pochart P, Marteau P, Flourie B, Bornet F \& Rambaud J-C (1999) Shortchain fructo-oligosaccharide administration dose-dependently increases fecal bifidobacteria in healthy humans. Journal of Nutrition 129, 113-116.

Buddington RK, Williams CH, Chen SC \& Whitherly SA (1996) Dietary supplement of neosugar alters the fecal flora and decreases activities of some reductive enzymes in human subjects. American Journal of Clinical Nutrition 63, 709-716.

Burke A, Lichtenstein GR \& Rombeau JL (1997) Nutrition and ulcerative colitis. Baillieres Clinical Gastroenterology 11, $153-174$

Campbell JM, Fahey GC \& Bryan WW (1997) Selected indigestible oligosaccharides affect large bowel mass, cecal and fecal short-chain fatty acids, $\mathrm{pH}$ and microflora in rats. Journal of Nutrition 127, 130-136.

Collins MD, Lawson PA, Willems A, Cordoba JJ, FernandezGarayzabal J, Garcia P, Cai J, Hippe H \& Farrow JAE (1994) The phylogeny of the genus Clostridium: proposal of five genera and eleven new species combinations. International Journal of Systematic Bacteriology 44, 812-826.

Cummings JH (1981) Short chain fatty acids in the human colon. Gut 22, 763-779.

Cummings JH, Beatty ER, Kingman SM, Bingham SA \& Englyst HN (1996) Digestion and physiological properties of resistant starch in the human large bowel. British Journal of Nutrition $\mathbf{7 5}$, $733-747$.

Cummings JH \& Macfarlane GT (1991) The control and consequences of bacteria fermentation in the human colon. Journal of Applied Microbiology 70, 443-459.

Cummings JH \& Macfarlane GT (1997) Role of intestinal bacteria in nutrient metabolism. Clinical Nutrition 16, 3-11.

Djouzi Z \& Andrieux C (1997) Compared effects of three oligosaccharides on metabolism of intestinal microflora in rats inoculated with a human faecal flora. British Journal of Nutrition 78, 313-324.

Franks AH, Harmsen HJM, Raangs GC, Jansen GJ, Shut F \& Welling GW (1998) Variations of bacterial populations in human feces measured by fluorescent in situ hybridization with group-specific 16S rRNA-targeted oligonucleotide probes. Applied and Environmental Microbiology 64, 3336-3345.

Gibson GR (1999) Dietary modulation of the human gut microflora using the prebiotics oligofructose and inulin. Journal of Nutrition 129, 1438S-1441S.

Gibson GR, Beatty EB, Wang X \& Cummings JH (1995) Selective stimulation of bifidobacteria in the human colon by oligofructose and inulin. Gastroenterology 108, 975-982.

Gibson GR \& Roberfroid MB (1995) Dietary modulation of the human colonic microbiota: introducing the concept of prebiotics. Journal of Nutrition 125, 1401-1412. 
Gibson GR \& Wang X (1994) Regulatory effects of bifidobacteria on the growth of other colonic bacteria. Journal of Applied Bacteriology 74, 667-674.

Hague A, Butt AJ \& Paraskeva A (1996) The role of butyrate in human colonic epithelial cells: an energy source or inducer of differentiation and apoptosis? Proceedings of the Nutrition Society 55, 937-943.

Harmsen HJM, Elfferich P, Shut F \& Welling G.W. (1999) A 16SrRNA-targeted probe for detection of lactobacilli and enterococci in faecal samples by fluorescent in situ hybridization. Microbial Ecology in Health and Disease 11, 3-12.

Hentges DJ (1967) Influence of $\mathrm{pH}$ on the inhibitory activity of formic and acetic acids for Shigella. Journal of Bacteriology $\mathbf{9 3}$, 2029-2030.

Hidaka H, Eida T, Takizawa T, Tokunaga T \& Tashiro Y (1986) Effects of fructooligosaccharides on intestinal flora and human health. Bifidobacteria Microflora 5, 37-50.

Jacobasch G, Schmiedl D, Kruschewski M \& Schmehl K (1999) Dietary resistant starch and chronic inflammatory bowel diseases. International Journal of Colorectal Diseases 14, 201-211.

Kleessen B, Noack J \& Blaut M (1999) Distribution of viable and non-viable bacteria in the gastrointestinal tract of gnotobiotic and conventional rats. Microbiology Ecology in Health and Disease 11, 218-225.

Kleessen B, Sykura B, Zunft H-J \& Blaut M (1997) Effects of inulin and lactose on fecal microflora, microbial activity, and bowel habit in elderly constipated persons. American Journal of Clinical Nutrition 65, 1397-1402.

Kruse H-P, Kleessen B \& Blaut M (1999) Effects of inulin on faecal bifidobacteria in human subjects. British Journal of Nutrition 82, 375-382.

Langendijk PS, Schut F, Jansen GJ, Raangs GC, Kamphuis GR, Wilkinson MHF \& Welling GW (1995) Quantitative fluorescence in situ hybridization of Bifidobacterium spp. with genus-specific $16 \mathrm{~S}$ rRNA-targeted probes and its application in fecal samples. Applied and Environmental Microbiology 61, 3069-3075.

Le Blay G, Michel C, Blottiere HM \& Cherbut C (1999) Prolonged intake of fructo-oligosaccharides induces a short-term elevation of lactic acid-producing bacteria and a persistent increase in cecal butyrate in rats. Journal of Nutrition 129, 2231-2235.

Manz W, Amann R, Ludwig W, Vancanneyt M \& Schleifer K-H (1996) Application of a suite of 16S rRNA-specific oligonucleotide probes designed to investigate bacteria of the phylum cytophaga-flavobacter-bacteroides in the natural environment. Microbiology 142, 1097-1106.

Manz W, Szewzyk U, Eriksson P, Amann R, Schleifer K-H \& Stenström TA (1993) In situ identification of bacteria in drinking water and adjoining biofilms by hybridization with $16 \mathrm{~S}$ and $23 \mathrm{~S}$ rRNA-directed fluorescent oligonucleotide probes. Applied and Environmental Microbiology 59, 2293-2298.

Mallet AK, Bearne CA, Roland IR, Farthing MJG, Cole CB \& Fuller R (1987) The use of rats associated with a human faecal flora as a model for studying the effect of diet on the human gut microflora. Journal of Applied Bacteriology 63, 39-45.

Massimino SP, McBurney MI, Field CJ, Thomson ABR, Keelan M, Hayek MG \& Sunvold GD (1998) Fermentable dietary fiber increases GLP-1 secretion and improves glucose homeostasis despite increased intestinal glucose transport capacity in healthy dogs. Journal of Nutrition 128, 1786-1793.

Menne E, Guggenbuhl N \& Roberfroid M (2000) Fn-type chicory inulin hydrolysate has a prebiotic effect in humans. Journal of Nutrition 130, 1197-1199.

Morita T, Kasaoka S, Hase K \& Kiriyama S (1999) Psyllium shifts the fermentation site of high-amylose cornstarch toward the distal colon and increases fecal butyrate concentration in rats. Journal of Nutrition 129, 2081-2087.

Poulsen LK, Licht TR, Rang C, Krogfelt KA \& Molin S (1995) Physiological state of $E$. coli $\mathrm{BJ} 4$ growing in the large intestines of streptomycin-treated mice. Journal of Bacteriology 177, $5840-5845$

Prosky L, Asp N-G, Schweizer TF, De Vries J \& Furda I (1988) Determination of insoluble, soluble, and total dietary fiber in foods and food products: interlaboratory study. Journal of the Association Analytical Chemists 71, 1017-1023.

Rao AV (1999) Dose-response effects of inulin and oligofructose on intestinal bifidogenesis effects. Journal of Nutrition 129 , $1442 S-1445 S$

Reddy SR, Hamid R \& Rao CV (1997) Effect of dietary oligofructose and inulin on colonic preneoplastic aberrant crypt foci inhibition. Carcinogenesis 18, 1371-1374.

Roberfroid MB (1997) Health benefits of non-digestible oligosaccharides. Advances in Experimental Medical Biology 427, 211-219.

Roberfroid MB (2000) Prebiotics and probiotics: are they functional foods? American Journal of Clinical Nutrition 71, Suppl., 1682S-1687S.

Roberfroid MB \& Delzenne NM (1998) Dietary fructans. Annual Review of Nutrition 18, 117-143.

Roberfroid MB, Van Loo JA \& Gibson GR (1998) The bifidogenic nature of chicory inulin and its hydrolysis products. Journal of Nutrition 128, 11-19.

Roediger WEW (1995) The place of short-chain fatty acids in colonocyte metabolism in health and ulcerative colitis: the impaired colonocyte barrier. In Physiological and Clinical Aspects of Short-Chain Fatty Acids, pp. 337-351 [JH Cummings, JL Rombeau and T Sakata, editors]. Cambridge: University Press.

Rumney CJ \& Rowland IR (1992) In vivo and in vitro models of the human colonic flora. Critical Reviews in Food Science and Nutrition 31, 299-331.

Sakata T (1987) Stimulatory effect of short-chain fatty acids on epithelial cell proliferation in the rat intestine: a possible explanation for trophic effects on fermentable fibre, gut microbes and luminal trophic factors. British Journal of Nutrition 58, 95-103.

Sghir A, Chow JM \& Mackie RI (1998) Continuous culture selection of bifidobacteria and lactobacilli from human faecal samples using fructooligosaccharide as selective substrate. Journal of Applied Microbiology 85, 769-777.

Simpson EJ, Chapman MAS, Dawson J, Berry D, Macdonald A \& Cole A (2000) In vivo measurement of colonic butyrate metabolism in patients with quiescent ulcerative colitis. Gut $\mathbf{4 6}$, $73-77$.

Smith JG, Yokoyama WH \& German JB (1998) Butyric acid from the diet: Actions at the level of gene expression. Critical Reviews in Food Science and Nutrition 38, 259-297.

Tappenden KA, Drozdowski LA, Thomson ABR \& McBurney MI (1998) Short-chain fatty acid-supplemented total parenteral nutrition alters intestinal structure, glucose transporter 2 (GLUT2) mRNA and protein, and proglucagon mRNA abundance in normal rats. American Journal of Clinical Nutrition 68, 118-125.

Treem WR, Ahsan N, Shoup M \& Hyams JS (1994) Fecal shortchain fatty acids in children with inflammatory bowel disease. Journal of Pediatric Gastroenterology and Nutrition 18 , $159-164$

Van Loo J, Coussement P, De Leenheer L, Hoebregs H \& Smits G (1995) On the presence of inulin and oligofructose as natural ingredients in the Western diet. Critical Reviews in Food Science and Nutrition 35, 525-552.

Van Loo J, Cummings J, Delzenne N, Englyst H, Franck A, 
Hopkins M, Kok N, Macfarlane G, Newton D, Quigley M, Roberfroid M, Van Vliet T \& Van den Heuvel E (1999) Functional food properties of non-digestible oligosaccharides: a consensus report from the ENDO project (DGXII AIRIICT94-1095). British Journal of Nutrition 81, 121-132.

Velazquez OC, Lederer HM \& Rombeau JL (1996) Butyrate and the colonocyte. Implications for neoplasia. Digestive Disease and Science 41, 729-739.

Wang X \& Gibson GR (1993) Effect of the in vitro fermentation of oligofructose and inulin by bacteria growing in the human large intestine. Journal of Applied Bacteriology 75, 373-380.

Weaver GA, Krause JA, Miller TL \& Wolin MJ (1988) Short chain fatty acid distributions of enema samples from a sigmoidoscopy population: an association of high acetate and low butyrate ratios with adenomatous polyps and colon cancer. Gut 29, 1539-1543.

Welling GW, Elfferich P, Raangs GC, Wildeboer-Veloo ACM, Jansen GJ \& Degener JE (1997) 16S rRNA-targeted oligonucleotide probes for monitoring of intestinal tract bacteria. Scandinavian Journal of Gastroenterology 32, Suppl. 222, 17-19.

Wilcoxon F \& Wilcox RA (1964) Some Rapid Approximate Statistical Procedures, New York, NY: Lederle Laboratories.

Zar JH (1984) Biostatistical Analysis, 2nd ed, New York, NY: Prentice-Hall. 